\title{
Cost Savings through Clinical Care Pathways in Austria, Poland, and the Slovak Republic
}

J. Lopez (Joshua Lopez), B. Ramirez (Bernardo Ramirez)

University of Central Florida, College of Health and Public Affairs,

Department of Health Management and Informatics

\section{E-mail address:}

lopezjo10@outlook.com

\section{Reprint address:}

Joshua Lopez

University of Central Florida

College of Health and Public Affairs

Department of Health Management and Informatics

4364 Scorpius St., HPA2-210, Orlando, FL 32816-2205

Suource: Clinical Social Work and Health Intervention

Pages: $38-43$

Volume: 8

Issue: 2

\section{Reviewers:}

Daniel J. West, Jr.

University of Scranton, Department of Health Administration and Human Resources

Zofia Szarota

Pedagogical University of Cracow, Poland

\section{Key words:}

Clinical pathways, Evidence based medicine, Chronic Obstructive Pulmonary Disorder (COPD), Cost savings.

\section{Publisher:}

International Society of Applied Preventive Medicine i-gap

CSWHI 2017; 8(2): 38 - 43; 10.22359/cswhi_8_2_08 @ 2017 Clinical Social Work and Health Intervention

\section{Abstract:}

Health and wellness represents the largest economic sector activity of this 21 st Century. It is a multidisciplinary arena that requires evidence-based Medical and Management Science to improve clinical practice, health, value, and outcomes. While great advances have been made in recent years, clinical protocols and guidelines could 
be implemented more effectively to achieve reduced costs and better clinical results. The increased complexity of health systems and new healthcare technologies combined with changing demographic factors such as extended longevity and a greater burden of chronic illnesses make the better use of evidence-based guidelines indispensable to manage disease. This paper presents as an example the analysis of clinical pathways for patients with Chronic Obstructive Pulmonary Disorder (COPD) to increase the effectiveness and efficiency in healthcare delivery by improving results that can be observed through reductions in variations in treatment; reductions in over-testing; over-prescription; improvements in health outcomes; quality of care.

\section{Introduction}

Health and wellness of individuals has become an issue of growing global concern. As a result, Epidemiologists, Medical Doctors, Scientists and political figures have worked tirelessly to improve the overall health of individuals. While great strides have been made, there is still room for improvement. More specifically, the region commonly referred to as Central Europe has struggled to maintain healthy lifestyles. As the population continues to age, the increasing prevalence of chronic diseases has challenged the efficiency and effectiveness of existing routine interventions. High tobacco use rates; high saturated fat consumption; high obesity rates have become major risk factors in the development of numerous cancers and chronic respiratory diseases. Costs of care have not been the most favorable either. In fact, annual costs in European Union (EU) Countries due to COPD is 48 billion euro and 34 billion euro for asthma (Bousquet et al. 2014). In addition, the three highest mortality rates for individuals with cancer ages 0-64 years are present in Hungary, the Slovak Republic, and Poland (European Observatory 2011). These alarming statistics suggest that an effective and efficient healthcare system should rely on early diagnosis and immediate, effective treatment. Currently, healthcare spending is on the rise, with a significant portion of spending absorbed by pharmaceutical spending in the Slovak Republic (Micieta 2012).

There are plenty of opportunities for cost savings and cost reduction initiatives in the management of these chronic diseases. The solution lies in the utilization and implementation of integrated care pathways. As seen in Figure 1, Evidence-Based Practice (EBP) can be achieved when Clinical Expertise, Best Research Evidence, and Patient values and Preferences are combined. These care pathways utilize evidence-based research to determine the correct treatment, at the correct time, in the correct setting. This three point goal approach promotes quality-driven care paired with proper coordination of services. As a result, cost savings can be observed through reductions in variations in treatment; reductions in over-testing; over-prescription; improvements in health outcomes; quality of care (Evans-Lacko et al. 2010).

\section{Methods}

The findings for this study were collected as secondary research. The goal of this research was to find information regarding the presence of clinical pathways in Central Europe, but also to determine the cost savings observed through their utilization. Clinical pathways can be used in any healthcare setting and across all disciplines. In some cases in the region, clinical pathways have 
become the standard of care in the fields of Oncology and Palliative care (Bousquet et al. 2014). One significant opportunity for the region relates to acute and chronic respiratory diseases. varied between countries. Polish Physicians were more likely to prescribe amoxicillin, while Slovak Physicians were more likely to prescribe macrolides.

Figure 1: Evidence Based Practice Main Elements

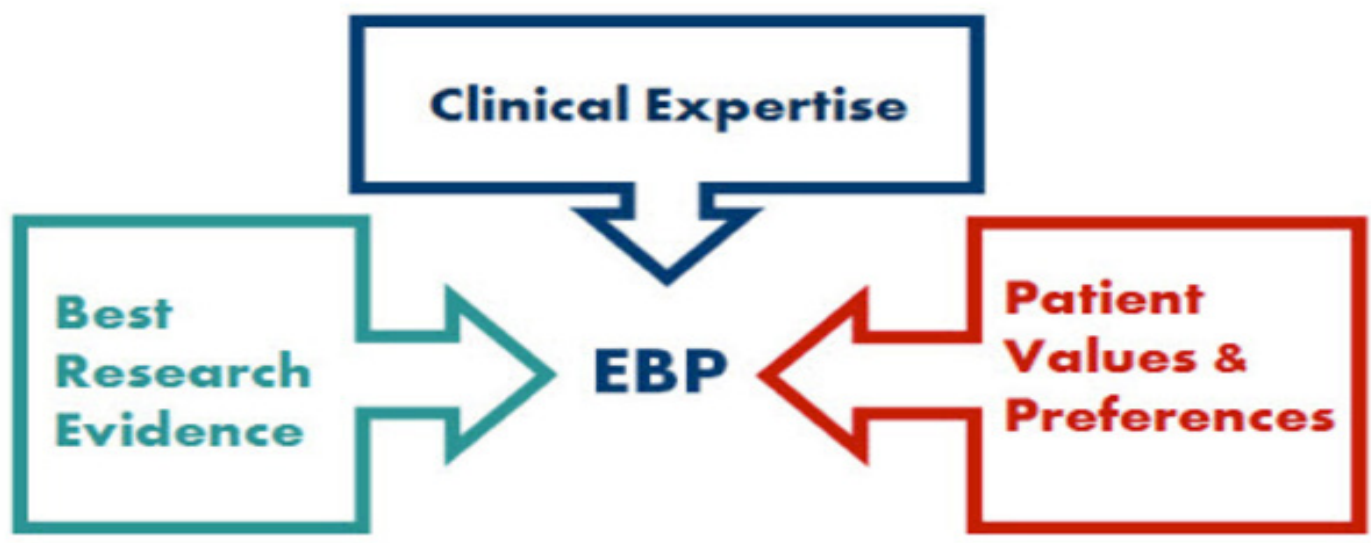

\section{Results}

In the primary care setting, one study published in $B M J$ focused on adults across 13 European Countries with a new onset of or worsening cough, or a clinical presentation suggestive of a lower respiratory tract infection (Butler et al. 2009). These patients were followed for up to one month, where data was collected and analyzed over the course of treatment and continuously to monitor its effects. Antibiotic prescribing for this clinical presentation varied by country, ranging from $20 \%$ to nearly $90 \%$ of all visits with the overall mean being $53 \%$ (Butler et al. 2009). It was determined that patients in the Slovak Republic and Poland were twice as likely to be prescribed antibiotics as the overall mean. In fact, $71 \%$ of patients in Poland were prescribed antibiotics compared to $87 \%$ of patients in the Slovak Republic (Butler et al. 2009). The difference in type of antibiotic prescribed also
Unfortunately, antibiotic prescriptions were not associated with significant differences in recovery based on the antibiotic prescribed (Butler et al., 2009). Therefore, financial implications of these variations may be harmful. Resources are wasted due to the different antibiotics being prescribed, where one antibiotic does not show a more rapid increase in recovery over another. Also, costs of these antibiotics can range from generic to very expensive prices per dose, so Physicians should be aware of the antibiotics being prescribed. In addition, self-care and a more holistic approach for similar conditions in the future may be compromised due to patient expectation of a prescription whenever they have a cough. It is imperative that patients with a cough are properly treated in order to avoid the progression into a more serious, chronic condition, such as COPD. 
The prevalence of Chronic Obstructive Pulmonary Disorder is increasing steadily, with over 350,000 patients in the Slovak Republic each year (Ondrusova et al. 2014). Additionally, 10,000 deaths in the Slovak Republic are attributed to the disease (Ondrusova et al., 2014). COPD is a condition that progressively worsens over time. As air flows in and out of the lungs, the amount of air diminishes due to one or more of the following reasons:

- destroyed walls in air sacs,

- inflamed and thick walls of the airways,

- clogging of the airways due to excessive mucus production,

- the airways and air sacs losing their elasticity (Koblizek et al. 2013).

Smoking and other long-term exposure to lung irritants are the main causes of COPD (Osinova et al. 2015). Costs of treatment in the EU due to COPD are approximately 48 billion euros (Bousquet et al. 2014). Another common risk factor for COPD among children and adults is asthma, which accounts for 34 billion euros across the EU (Bousquet et al. 2014).

The Global Initiative for Chronic Obstructive Lung Disease (GOLD) was introduced in 2007 (Osinova et al. 2015). Since then, many revisions have been made according to updates in evidence-based research. This initiative is a four step approach to care for these patients.

1. assess and monitor disease. Early identification of symptoms such as cough, sputum production, dyspnea, and/or history of exposure to risk factors is the first step in halting the progression of COPD (Vestbo et al. 2013).

2. reduce risk factors such as smoking and occupational exposures.
3. manage stable COPD, usually with bronchodilators but more specifically with patient education (Vestbo et al., 2013).

4. exacerbations (i.e. sudden worsening of symptoms) should be managed and kept to a minimum.

Despite ongoing efforts to implement this initiative, cost containment and mortality are still major issues in the region.

\section{Discussion}

The Slovak Republic's Healthcare System can be one that is described as overburdened. Health expenditures have increased between 2000 and 2012 from 5.5\% of GDP to $8.1 \%$ of GDP (OECD 2016). Likewise, health expenditure per capita and pharmaceutical expenditure per capita have increased. In fact, pharmaceutical spending accounts for $28 \%$ of all Healthcare spending, almost two times higher than the Organization for Economic Co-operation and Development (OECD) average (Micleta 2012). Many countries in the region are feeling overburdened as well. Healthcare spending is on the rise in Central Europe. Most notably, Austria currently spends 4,381 euros on Healthcare, significantly higher than the average of 2,800 euros among developed countries (OECD 2016). Meanwhile, pharmaceutical spending remains a major factor for Poland, slightly above OECD average at $20.9 \%$ of healthcare spending. Austria remains below the OECD average at $12 \%$ of Healthcare spending (OECD 2016).

Costs associated with COPD are categorized into four stages: Mild COPD, Moderate COPD, Severe COPD, and Very Severe COPD. The National Health Information Center Reported that approximately $76 \%$ of patients fall into the mild or moderate COPD category (Ondrusova et al. 2015). Almost 
$5 \%$ of patients are categorized as very severe COPD. However, these patients are almost exclusively hospitalized, with costs associated with treatment being over 10 times that of mild COPD patients (Ondrusova et al. 2015).

These statistics suggest that the efficiency and effectiveness of treatment must be at the forefront of Healthcare delivery to achieve better results and stability in Austria, Poland, and the Slovak Republic. Implementing clinical pathways in acute and chronic respiratory diseases will have many financial and quality-driven benefits.

First, it will introduce and capture a common clinical framework for acute and chronic respiratory diseases. Physicians will have a common tool through which they can practice, stratify patients by risk, and draw on educational materials for patients and other stakeholders (Bousquet et al. 2014).

Secondly, care pathways reduce the overburden of healthcare delivery. With the implementation of clinical pathways, morbidity is reduced and education is encouraged in the short run, while a reduction in emergency visits and avoidable hospitalizations can be observed long run.

In Spain, Miratvitlles et al. conducted a retrospective study comparing the economic impact for those who did not adhere to the therapeutic recommendations of the GOLD Initiative based on COPD severity (2013). The authors discovered that compliant patients with stage II COPD paid $€ 426.40$ in total annual drug costs per patient. Those who were non-compliant paid $€ 771.5$, nearly a two-fold difference. In addition, the average direct cost per patient per year was $€ 1,465$ (Miratvitlles et al. 2013). By implementing the GOLD initiative in Austria, Poland, and the Slovak Republic, patients with stage II COPD would experience a savings of $€ 758$ per patient annually, which would also include a $68 \%$ savings on the cost of drugs (Miratvitlles et al. 2013). Therefore, it is imperative that these guidelines are used as early as possible, as the same study also suggests that the cost for patients with stage III disease was higher in those not adhering to the GOLD initiative standards versus those who were.

\section{Conclusion}

The prevalence of clinical pathways has increased dramatically across the globe. Countries have become more aware of the need for producing high quality care at an affordable cost. Barriers to cost effectiveness include but are not limited to variations in treatment; over-testing; over-prescribing; lackluster health outcomes across various populations. Acknowledgement of these trends and observing them across a region such as Austria, Poland, and the Slovak Republic is the first stage in implementing a clinical pathway. Rising costs and efforts to manage lifestyle factors and chronic diseases in Central Europe have called the efficiency and effectiveness of current treatment practices into question. The concept of clinical pathways is one that healthcare providers and managers are utilizing as a solution to this issue. Clinical pathways are iterative, so they constantly go through a cycle of planning, implementation, analysis, and re-evaluation (Evans-Lacko et al. 2010). This process allows for the most up-to-date treatment options that improve patient outcomes. Medical professionals argue that these standardized clinical pathways for patient conditions will clearly define a process for treatment, one that uses evidence-based medicine and provides clear expectations of care for the patient. This process can also be used to measure the progress of patient recovery and, in some cases become a method for hospital and physician reimbursement in the years to come (Evans-Lacko et al. 2010). 


\section{Reference}

1. BOUSQUET J ET AL (2014). Integrated care pathways for airway diseases (AIRWAYS-ICPs).

2. BUTLER C, HOOD K, VERHEIJ T, LITTLE P, MELBYE H, NUTTALL J, ... GOOSSENS H (2009) Variation in antibiotic prescribing and its impact on recovery in patients with acute cough in primary care: Prospective study in 13 countries. BMJ (Online), 338(7710), 1545.

3. EUROPEAN OBSERVATORY ON HEALTH SYSTEMS \& POLICIES (2011). Slovakia Health System Review. Health Systems in Transition, Vol. 13, No 2, 2011. Retrieved http://www.euro.who.int/_data/assets/pdf_ file/0004/140593/e94972.pdf?ua=1.

4. EVANS-LACKO S, JARRETT M, MCCRONE P, THORNICROFT G (2010). Facilitators and barriers to implementing clinical care pathways. Bmc Health Services Research, 10.

5. KOBLIZEK V, CHLUMSKY J, ZINDR V, NEUMANNOVA K, ZATLOUKAL J, ZAK J, ... PRACHAROVA S (2013). Chronic Obstructive Pulmonary Disease: Official diagnosis and treatment guidelinesof the Czech Pneumological and Phthisiological Society; a novel phenotypic approach to COPD with patient-oriented care. Biomedical Papers-Olomouc, 157(2), 189-201.

6. MICIETA V (2012). Focus on care pathways is the way to stabilize Slovak Healthcare. Amcham Connection. 3.

7. MIRAVITLLES M, SICRAS A, CRESPO C, CUESTA M, BROSA M, GALERA J, ... RIERA MI (2013). Costs of chronic obstructive pulmonary disease in relation to compliance with guidelines: a study in the primary care setting. Therapeutic Advances In Respiratory Disease, 7(3), 139-150.

8. ONDRUSOVA M, PSENKOVA $\mathrm{M}$, MACKOVICOVA, S (2014). Resource Use and Health Care Costs of Chronic Obstructive Pulmonary Disease in Slovakia. Value In Health, 17(7), A594-A595.

9. ORGANIZATION FOR ECONOMIC COOPERATION AND DEVELOPMENT (OECD). (2016). Retrieved from https:// data.oecd.org/slovak-republic.htm\#profile-health and all indicators in Health: https://data.oecd.org/searchresults/? $\mathrm{r}=\% 2 \mathrm{~B}-$ $\mathrm{f} \% 2$ Ftype $\% 2$ Findicators $\& \mathrm{r}=02 \mathrm{Bf} \% 2$ Ftopics_en $\% 2$ Fhealth.

10. OSINOVA D, SADLONOVA J, ROZBORILOVA E (2015). Exacerbations of Chronic Obstructive Pulmonary Disease and Implementation of Guidelines Gold 2011 in Practice. Acta Medica Martiniana, 15(2), 13-20.

11. BAK T, MIERZWA J, JURJEWICZ H (2015). Religion and Spirituality in Social Work Practice. New Jersey 2015. 101 s. ISBN 978-0-9967396-2-7.

12. BELOVICOVA M, ADAMCOVA J, KAFKOVA J ET ALL (2017). Low incidence of MRSA among úphysiotherapy patients. Clin Soc Work Health Intervention, vol.8.2017,1,33-35. ISSN 2076-9741/Online.

13. VESTBO J, HURD S S, AGUSTI A G, JONES P W, VOGELMEIER C, ANZUETO A, ... RODRIGUEZ-ROISIN R (2013). Global Strategy for the Diagnosis, Management, and Prevention of Chronic Obstructive Pulmonary Disease: GOLD Executive Summary. American Journal Of Respiratory \& Critical Care Medicine, 187(4), 347-365. 